\title{
Review \\ Optimization of RAASi Therapy with New Potassium Binders for Patients with Heart Failure and Hyperkalemia: Rapid Review and Meta-Analysis
}

\author{
Andrea Montagnani ${ }^{1, *}$, , Stefania Frasson ${ }^{2}$, Gualberto Gussoni ${ }^{2}$ and Dario Manfellotto ${ }^{3}$ \\ 1 Internal Medicine, Hospital of Grosseto, 58017 Grosseto, Italy \\ 2 FADOI Research Centre, 20123 Milan, Italy; stefania.frasson@fadoi.org (S.F.); \\ gualberto.gussoni@gmail.com (G.G.) \\ 3 Department of Internal Medicine, Hospital "Fatebenefratelli-AFaR", 00186 Rome, Italy; \\ dario.manfellotto@afar.it \\ * Correspondence: montagnaniand@gmail.com; Tel.: +39-338-222-7708
}

Citation: Montagnani, A.; Frasson, S.; Gussoni, G.; Manfellotto, D. Optimization of RAASi Therapy with New Potassium Binders for Patients with Heart Failure and Hyperkalemia: Rapid Review and Meta-Analysis. J. Clin. Med. 2021, 10, 5483. https:// doi.org/10.3390/jcm10235483

Academic Editor: Micha Maeder

Received: 17 September 2021

Accepted: 19 November 2021

Published: 23 November 2021

Publisher's Note: MDPI stays neutral with regard to jurisdictional claims in published maps and institutional affiliations.

Copyright: (C) 2021 by the authors. Licensee MDPI, Basel, Switzerland. This article is an open access article distributed under the terms and conditions of the Creative Commons Attribution (CC BY) license (https:/ / creativecommons.org/licenses/by/ $4.0 /)$.

\begin{abstract}
Background: The objective of this rapid review is to assess whether new potassium binders (NPBs) could enable the optimization of RAASi therapy more than usual care or placebo in patients with or at risk of heart failure and hyperkalemia. (2) Methods: We searched for RCTs that included patients with or at risk of hyperkalemia and patients treated with Patiromer or sodium zirconium cyclosilicate (ZSC). The comparators were placebo, usual care, and potassium binders with different doses or different treatment protocols. We searched the Cochrane CENTRAL, MEDLINE, and ClinicalTrials.gov databases. The risk of bias was assessed using the Cochrane risk of bias tool for RCTs. Data were pooled using the random effects model, and the fixed effects model was used for sensitivity analysis. (3) Results: We included 12 studies with 2800 enrolled patients. Only three of these trials (412 patients) were included in the meta-analysis. NPBs seemed to have an effect on the optimization of MRA therapy, with an RR $(95 \%$ CI) of $1.24(1.09,1.42)$ (moderate certainty evidence); Patiromer seemed to have an effect on MRA optimization, with an RR $(95 \% \mathrm{CI})$ or $1.25(1.08,1.45)$ (high certainty evidence). ZSC seemed to have no effect on enabling MRA therapy, with an RR (95\% CI) of $1.19(0.89,1.59)$ (low certainty evidence). The AEs in HF patients with hyperkalemia treated with Patiromer were GI disorders and hypomagnesemia. ZSC The AEs included chronic cardiac failure, hypokalemia, and edema. (4) Conclusions: This meta-analysis included three studies with a small number of patients and a short follow-up period (1-3 months). The evidence of the effect of NPBs on MRA optimization had a moderate certainty for imprecision. Data on the effect on MRA optimization and less severe AEs in long-term treatment seem to suggest the use of Patiromer for the optimization of MRA therapy in patients with or at risk of heart failure and hyperkalemia. Future adequately powered RCTs are needed to assess the benefits and potential harms of potassium binders.
\end{abstract}

Keywords: hyperkalemia; Patiromer; sodium zirconium cyclosilicate; meta-analysis; heart failure; RAAS

\section{Introduction}

\subsection{Description of the Condition}

RAASi therapy (ACEi, ARB, MRA, and ARNi therapy) is the cornerstone therapy for patients with heart failure with reduced ejection fraction (HFrEF). International guidelines recommend RAAS inhibitors because of strong evidence [1,2]. Even so, there are some barriers to the implementation of this therapy, including hypotension, kidney dysfunction, and hyperkalemia (HK) [3]. HK is defined as high serum potassium $\left(\mathrm{K}^{+}\right)$levels. There is no universal cutoff for $\mathrm{HK}$, but a level of $5.0 \mathrm{mEq} / \mathrm{L}$ is common [4]. HK is a life-threatening condition that leads to significant morbidity and mortality. A recent evaluation of medical records demonstrated an increase in all-cause mortality both with $\mathrm{K}^{+}$values below the 
normal range and values higher than $5.5-6.0 \mathrm{mEq} / \mathrm{L}$, with a clear effect of comorbidities, such as diabetes, heart failure, and CKD, considered individually or together [5]. In three pivotal clinical studies examining the efficacy of RAAS inhibitors in heart failure, HK occurred in these patients at a non-negligible frequency, although patients with a high risk of HK (i.e., with impaired renal function) were excluded from the studies [6-8].

The latest ESC guidelines recommend that RAAS inhibitors should be administered at the maximum recommended dose in order to achieve a positive effect on mortality in patients with HFrEF [1]. The protective effect of RAAS inhibitors on mortality in patients with heart failure is maximized when used in combination, but at the same time, a higher risk of HK, and therefore a worse outcome, is caused by using a combination with a suboptimal dose of RAASi. In addition, patients who appear to benefit from the administration of RAAS inhibitors also have a higher risk of HK [9]. Recently, Rossignol et al. published data from 9222 patients with chronic heart failure in the ESC-HFA-EORP Heart Failure Long-Term Registry, confirming the association between HK and mortality. However, when the same data were adjusted for RAAS inhibitor discontinuation, HK was no longer associated with mortality, suggesting that HK may be a risk marker for RAAS inhibitor discontinuation rather than a risk factor for poorer outcomes [10]. In an unpublished survey that the Federation of Hospital Internists (FADOI) carried out among approximately 300 Italian internists in 2020, RAAS inhibitors were discontinued by $80 \%$ of physicians when potassium was more than $5.5 \mathrm{mEq} / \mathrm{L}$ or down-titrated when potassium serum values were higher than $5.0 \mathrm{mEq} / \mathrm{L}$. This conservative and cautious approach seems to be common since HK is correlated with higher mortality; however, it induces a lack of optimization of therapy in patients with heart failure and/or CKD who are treated with RAAS inhibitors, with a consequent increase in mortality [11].

\subsection{Description of the Intervention}

Two new drugs have been developed to treat HK: Patiromer and sodium zirconium cyclosilicate (SZC). Patiromer is a spherical, non-resorbed, metal-free, cross-linked fluoroacrylate polymer [12]. Sodium zirconium cyclosilicate is a non-absorbed, non-polymeric inorganic powder with a uniform microporous structure [13].

\subsection{How the Intervention Might Work}

Most potassium is eliminated through the kidneys, but $5-10 \%$ is eliminated in the colon. Both Patiromer and SZC remove potassium by exchanging cations (calcium and sodium for Patiromer and SZC, respectively) for potassium in the gastrointestinal tract, binding potassium and increasing its fecal excretion. Patiromer was developed to provide a higher potassium binding capacity compared with the polystyrene sulfonate polymer. It has improved physical properties, such as a low swell ratio that allows for minimal water uptake, and, importantly, Patiromer uses calcium rather than sodium as the exchange cation. Patiromer was completely ionized for optimal ion exchange at the physiological $\mathrm{pH}$ of the large intestine, where the potassium concentration in the gastrointestinal tract was the highest [12]. Sodium zirconium cyclosilicate is highly selective for potassium ions in vitro, even in the presence of other cations, such as calcium and magnesium. Sodium zirconium cyclosilicate traps potassium throughout the gastrointestinal tract (GI) and reduces the concentration of free potassium in the GI lumen, thereby lowering serum potassium and increasing fecal potassium excretion to resolve HK [13].

\subsection{Why It Is Important to Do This Review}

Although several systematic reviews have examined the efficacy of these new compounds in lowering serum potassium [14-17], no SRs have analyzed whether NPBs allow the optimization of RAASi therapy in HF patients. This is the first quick review in this area. 


\subsection{Objectives}

The objective of this rapid review was to assess whether new potassium binders (NPBs) could enable the optimization of RAASi therapy more than usual care or placebo in patients with or at risk of heart failure and HK.

\section{Materials and Methods}

\subsection{Criteria for Considering Studies for this Review}

\subsubsection{Types of Studies}

We included RCTs published in English before the end of July 2021; we also included studies that were not published but had results available in the international registry of clinical trials. We chose only RCTs because this was a reference design study for the evaluation of treatments.

\subsubsection{Types of Participants}

We included studies with patients with or at risk of HK.

\subsubsection{Types of Interventions}

We included patients treated with a Patiromer or sodium zirconium cyclosilicate. The comparators in the studies were placebo, usual care, and potassium binders with different doses or different treatment protocols. We excluded studies with SPS and CPS and extension studies without comparators.

\subsubsection{Types of Outcome Measures}

Primary outcomes:

- Proportion of patients on MRA therapy (guideline target dose) compared with placebo at the end of the study

- Proportion of patients on ACE/ARB therapy (guideline target dose) compared with placebo at the end of the study

Secondary outcomes

- Proportion of patients on ARNi therapy (guideline target dose) compared with placebo at the end of the study

- Safety of treatments in patients with heart failure

\subsection{Search Methods for Identification of Studies}

Electronic searches: We searched data in Cochrane CENTRAL, MEDLINE (via PubMed), and ClinicalTrials.gov. We searched for the terms "Patiromer" or "sodium zirconium cyclosilicate". In PubMed, we used ("Patiromer" [Supplementary Concept]) OR "sodium zirconium cyclosilicate" [Supplementary Concept]. In the Cochrane Library, we searched the terms "Patiromer in Title Abstract Keyword OR sodium zirconium cyclosilicate in Title Abstract Keyword" (word variations were searched).

\subsection{Data Collection and Analysis}

Selection of Studies

We used a standardized title and abstract form of title and abstract screening; two reviewers conducted dual screening of at least $20 \%$ of the abstracts with conflict resolution, and one reviewer conducted the screening of the remaining abstracts. A second reviewer checked all excluded abstracts and resolved the conflicts. One reviewer checked all included full-text articles, and a second reviewer checked all excluded full-text articles.

\subsection{Data Extraction and Management}

We recorded the number of HF patients in the studies, treatments (type and dose), comparators, and patients on RAASi at the end of the study. Data were extracted from the original publication or the substudy publication. 


\subsection{Assessment of Risk of Bias in Included Studies}

The risk of bias was assessed using the Cochrane Risk of Bias tool for RCTs [18]. A single reviewer rated the risk of bias, with a full verification of all judgments (and support statements) conducted by a second reviewer. We limited the risk of bias ratings to outcomes.

\subsection{Measures of Treatment Effect}

For dichotomous outcomes (optimization of MRA, ACEi/ARB, and ARNi therapies), the results are expressed as risk ratios (RRs) between groups with $95 \%$ confidence intervals (CIs).

\subsection{Assessment of Heterogeneity}

We assessed clinical heterogeneity by determining whether participant characteristics, interventions, outcomes measurements, and timing of outcome measurements were similar across the studies. We assessed the heterogeneity by visual inspection of the forest plots. Statistical heterogeneity was quantified using the I2 statistic, which describes the percentage of total variation between studies due to heterogeneity and not due to sampling errors [19]. We interpreted the I2 statistic as an approximate guideline as follows: $0 \%$ to $40 \%$, no important heterogeneity; $30 \%$ to $60 \%$, moderate heterogeneity; $50 \%$ to $90 \%$, considerable heterogeneity; and $75 \%$ to $100 \%$, considerable heterogeneity.

The significance of the observed value of I2 depends on the size and direction of the treatment effects and the strength of the evidence for heterogeneity (e.g., a $p$-value for the Chi-square test or a confidence interval for I2) [18]. If there was considerable heterogeneity, we examined the data further by comparing the characteristics of individual studies and subgroup analyses.

\subsection{Assessment of Reporting Biases}

To assess the publication bias, we created funnel plots when at least 10 studies examining the same treatment comparison were included in the review and commented on whether an asymmetry in the funnel plot was a publication bias or a methodological or clinical one. In order to evaluate potential effects in small studies in the meta-analysis (i.e., the intervention effect was more beneficial in smaller studies), we compared the effect estimates derived from a random effects model and a fixed effects model of the meta-analysis. In the case of small study effects, the random effects model could provide a more favorable estimate of the intervention than the fixed effects estimate.

\subsection{Data Synthesis}

The data were pooled with the random effects model, but the fixed effects model was used to ensure the robustness of the chosen model and the susceptibility to outliers. We used Review Manager (RevMan) (computer program) version 5.4, Cochrane Collaboration 2020 (Cochrane, London, UK).

\subsection{Subgroup Analysis and Investigation of Heterogeneity}

A subgroup analysis was performed to examine the possible sources of heterogeneity (if sufficient data were available). We chose to use the types of potassium binders as subgroups.

\subsection{Sensitivity Analysis}

We carried out sensitivity analyses in order to examine the influence of the effects model (random vs. fixed) on the effect size.

We also carried out sensitivity analyses to examine the influence of the following factors on the effect size:

- Repeating the analysis with the fixed effects model

- Repeating the analysis excluding studies with high risks of bias 


\section{Results}

\subsection{Description of Studies}

The electronic search results identified 334 records. After duplicating elimination, 159 records remained. We excluded 29 records: 25 were ongoing, 2 were unknown, and 2 had no results. After title and abstract screening of 130 records, we identified 12 studies (24 records). We excluded 106 full-text articles for the following reasons: four clinical cases, 11 comments, seven editorials, 10 letters, five systematic reviews, two observational studies, 51 reviews, five different languages, and five studies on animals.

We included 12 studies with 2800 patients enrolled. Only four studies included data on the use of RAAS inhibitor therapy at the end of the study (PRIORITIZE HF, AMBER, PEARL HF, and OPAL HK). Data on MRA therapy was present in 3 studies (PRIORITIZE HF, AMBER, and PEARL HF, 412 patients) and we included them in the meta-analysis. Data on the use of ACEi/ARB therapy in OPAL HK was reported separately. For two studies with Patiromer (AMBER and OPAL HK), we extracted data from publications on subgroups with heart failure [20,21] (Figure 1).

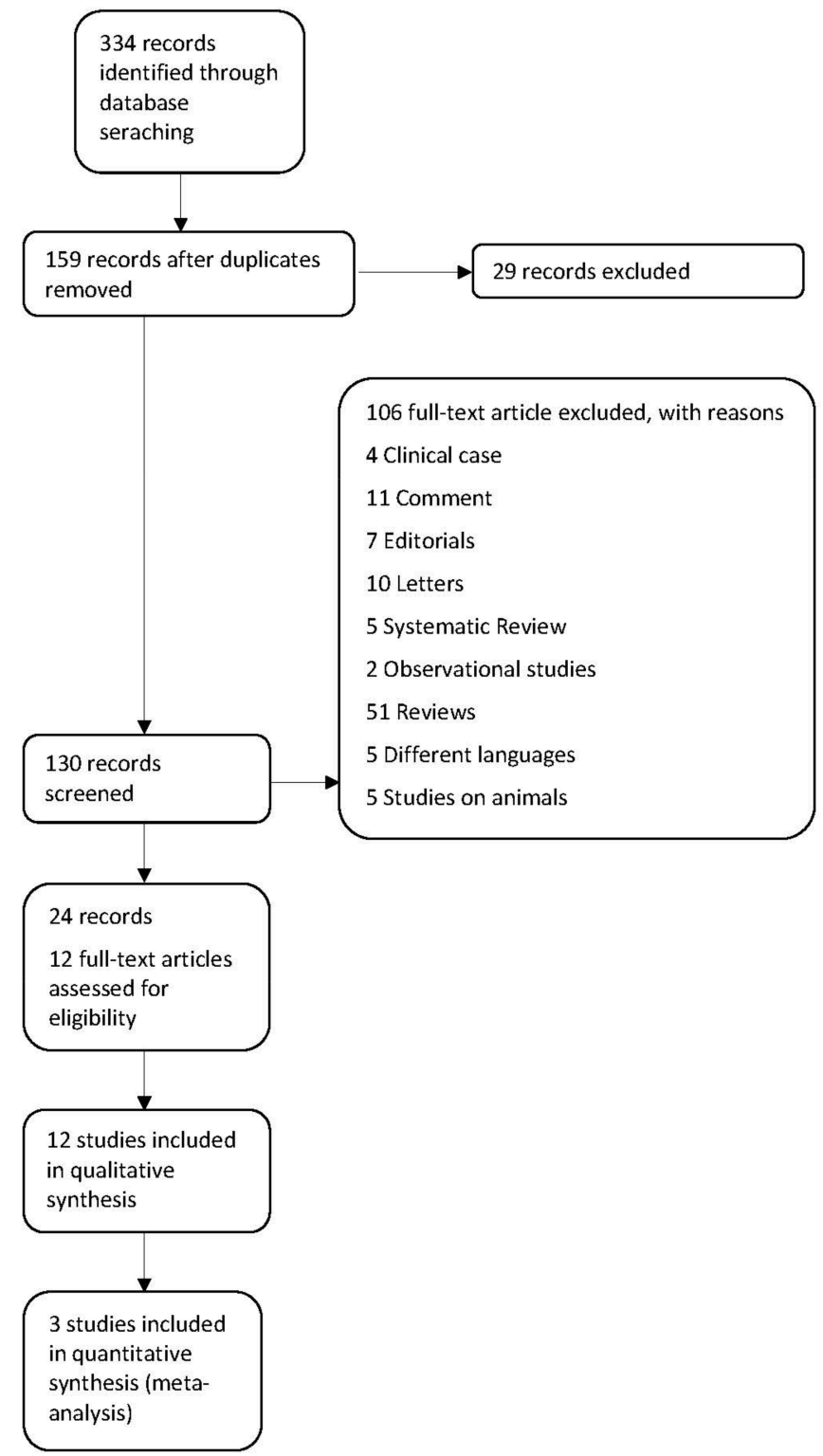

Figure 1. PRISMA flowchart. 


\subsection{Included Studies}

The studies included in the review are reported in Table 1.

Table 1. Studies included in the review.

\begin{tabular}{|c|c|c|c|c|}
\hline Study ID & Population & Intervention & Comparator & Outcome \\
\hline Agarwal, (AMBER) 2020 [22]. & $\begin{array}{l}295 \text { patients with CKD (eGFR } \\
\left.25 \text { to } 45 \mathrm{~mL} / \mathrm{min} / 1.73 \mathrm{~m}^{2}\right) \\
\text { and resistant hypertension, } \\
\text { baseline } \mathrm{K}^{+} \text {levels }(4.3 \text { to } \\
5.1 \mathrm{mmol} / \mathrm{L})\end{array}$ & Patiromer (8.4 g o.d.) & Placebo & $\begin{array}{l}\text { Proportion of patients } \\
\text { remaining on spironolactone }\end{array}$ \\
\hline Ash, 2015 [23]. & $\begin{array}{c}90 \text { outpatients, CKD stage } 3 \\
\text { and hyperkalemia (5.0 to } \\
6.0 \mathrm{mEq} / \mathrm{L})\end{array}$ & $0.3 \mathrm{~g}, 3 \mathrm{~g}, 10 \mathrm{~g}$ of ZSC & Placebo & $\begin{array}{l}\text { Rate of serum } \mathrm{K}^{+} \text {decline in } \\
\text { the first } 48 \mathrm{~h}\end{array}$ \\
\hline $\begin{array}{l}\text { Bakis, AMETHYST-DN, } 2015 \\
\text { [24] }\end{array}$ & $\begin{array}{c}306 \text { patients with T2DM } \\
\text { (eGFR, } 15 \text { to } \\
<60 \mathrm{~mL} / \mathrm{min} / 1.73 \mathrm{~m}^{2} \text { and } \\
\text { serum } \mathrm{K}^{+} \text {level }>5.0 \mathrm{mEq} / \mathrm{L} \text { ). }\end{array}$ & $\begin{array}{c}\text { Mild hyperkalemia: } 4.2 \mathrm{~g} \text {, } \\
\text { twice daily; moderate } \\
\text { hyperkalemia: } 8.4 \mathrm{~g} \text {, twice } \\
\text { daily }\end{array}$ & $\begin{array}{c}\text { Mild hyperkalemia: } \\
8.4 \text { g, or } 12.6 \text { g twice daily; } \\
\text { moderate hyperkalemia: } \\
12.6 \text { g, or } 16.8 \text { g twice daily }\end{array}$ & $\begin{array}{l}\text { Mean change in serum } \mathrm{K}^{+} \\
\text {from baseline to week } 4 \text { and } \\
\text { adverse events through } \\
52 \text { weeks }\end{array}$ \\
\hline Fishbane, DIALIZE 2019 [25]. & $\begin{array}{l}97 \text { patients with ESRD and } \\
\mathrm{HD} \text { three times weekly, } \\
\text { predialysis } \mathrm{sK}^{+}>5.4 \mathrm{mmol} / \mathrm{L} \\
\text { after the long interdialytic } \\
\text { interval as well as predialysis } \\
\mathrm{sK}^{+}>5.0 \mathrm{mmol} / \mathrm{L} \text { after at } \\
\text { least one short interdialytic } \\
\text { interval }\end{array}$ & ZSC $5 \mathrm{~g}, 10 \mathrm{~g}, 15 \mathrm{~g}$ & Placebo & $\begin{array}{l}\text { Patients with predialysis } \\
\text { serum } \mathrm{K}^{+} \text {of } 4.0-5.0 \mathrm{mmol} / \mathrm{L}\end{array}$ \\
\hline $\begin{array}{l}\text { Kosiborod, HARMONIZE } \\
2014 \text { [26]. }\end{array}$ & $\begin{array}{c}258 \text { patients with } \\
\text { hyperkalemia (serum } \\
\text { potassium } \geq 5.1 \mathrm{mEq} / \mathrm{L})\end{array}$ & $\begin{array}{c}\text { ZSC } 10 \mathrm{~g} \text { three times a day for } \\
48 \mathrm{~h} \text { (correction phase), after } \\
\text { which normokalemic patients } \\
(3.5-5.0 \mathrm{mEq} / \mathrm{L}) \text { were } \\
\text { randomized to ZSC, } 5 \mathrm{~g}, 10 \mathrm{~g} \text {, } \\
\text { or } 15 \mathrm{~g} \text { daily (Maintenance } \\
\text { phase) }\end{array}$ & Placebo & $\begin{array}{c}\text { Mean serum potassium level } \\
\text { in each zirconium } \\
\text { cyclosilicate group vs. } \\
\text { placebo in MP }\end{array}$ \\
\hline $\begin{array}{c}\text { Peacock WF, ENERGIZE } 2020 \\
\text { [27]. }\end{array}$ & $\begin{array}{l}70 \text { ED patients with blood } \\
\text { potassium } \geq 5.8 \mathrm{mmol} / \mathrm{L}\end{array}$ & SZC $10 \mathrm{~g}$ & Placebo & $\begin{array}{l}\text { Mean change in level of } \\
\text { serum } \mathrm{K}^{+} \text {from baseline until } \\
4 \mathrm{~h} \text { after the starting dose }\end{array}$ \\
\hline $\begin{array}{l}\text { Pergola, TOURMALINE, } 2017 \\
\text { [28]. }\end{array}$ & $\begin{array}{l}112 \text { patients with serum } \mathrm{K}^{+} \geq \\
5.0 \mathrm{mEq} / \mathrm{L}\end{array}$ & $\begin{array}{c}\text { Patiromer (by } \\
8.4 \mathrm{~g} / \text { day-25.2 g/day) with } \\
\text { food }\end{array}$ & $\begin{array}{c}\text { Patiromer } \\
(8.4 \mathrm{~g} / \text { day }-25.2 \mathrm{~g} / \text { day }) \\
\text { without food }\end{array}$ & $\begin{array}{c}\text { Proportion of patients } \\
\text { with level of serum } \mathrm{K}^{+} \text {in the } \\
\text { range of } 3.8-5.0 \mathrm{mEq} / \mathrm{L} \text { at } \\
\text { week } 3 \text { or } 4\end{array}$ \\
\hline Pitt, PEARL-HF, 2011 [29]. & $\begin{array}{c}105 \mathrm{HF} \text { patients with CKD } \\
\text { (eGFR }<60 \mathrm{~mL} / \mathrm{min}) \text { or a } \\
\text { history of } \mathrm{HK}\end{array}$ & Patiromer $25.2 \mathrm{~g}$ & Placebo & $\begin{array}{l}\text { Change from baseline in level } \\
\text { of serum } \mathrm{K}^{+} \text {at the end of } \\
\text { study }\end{array}$ \\
\hline PRIORITIZE HF 2021 [30] & $\begin{array}{l}182 \mathrm{HF} \text { patients with serum } \\
\text { potassium }>5.0 \mathrm{mmol} / \mathrm{L} \text { or at } \\
\text { high risk of hyperkalemia }\end{array}$ & ZSC $5 \mathrm{~g}$ or $10 \mathrm{~g}$ & Placebo & $\begin{array}{c}\text { Percentage of patients } \\
\text { receiving ACEi, ARB, MRA, } \\
\text { or ARNi treatments at month } \\
3\end{array}$ \\
\hline Rafique 2020 [31]. & $\begin{array}{l}30 \text { ESRD patients, serum } \mathrm{K}^{+} \\
\quad \geq 6.0 \mathrm{mEq} / \mathrm{L}\end{array}$ & Patiromer $25.2 \mathrm{~g}+\mathrm{SOC}$ & $\mathrm{SOC}$ & $\begin{array}{l}\text { Difference in serum } \mathrm{K}^{+} \\
\text {between groups at } 6 \mathrm{~h}\end{array}$ \\
\hline Weir, OPAL, 2015 [32] & $\begin{array}{c}\text { Initial phase: } 243 \text { CKD } \\
\text { patients in RAASi and with } \\
\text { serum } \mathrm{K}^{+} \text {levels between } 5.1 \\
\text { and } 6.5 \mathrm{mmol} / \mathrm{L} \text {. Withdrawal } \\
\text { phase: } 105 \text { patients in } \\
\text { normokalemic range }\end{array}$ & $\begin{array}{l}\text { Patiromer } 4.2 \mathrm{~g} \text { or } 8.4 \mathrm{~g} \\
\text { twice/day }\end{array}$ & Placebo in withdrawal phase & $\begin{array}{l}\text { Initial phase: mean change in } \\
\text { the serum } \mathrm{K}^{+} \text {level from } \\
\text { baseline to week } 4 . \\
\text { Withdrawl phase: } \\
\text { between-group difference in } \\
\text { the median change in the } \\
\text { serum } \mathrm{K}^{+} \text {level }\end{array}$ \\
\hline $\begin{array}{l}\text { Zannad, HARMONIZE } \\
\text { GLOBAL, } 2020 \text { [33]. }\end{array}$ & $\begin{array}{l}267 \text { patients with serum } \mathrm{K}^{+} \geq \\
5.1 \mathrm{mmol} / \mathrm{L}\end{array}$ & $\begin{array}{l}\text { CP: ZSC } 10 \mathrm{~g} 3 \text { times a day for } \\
48 \mathrm{~h} \text {. MP: ZSC } 5 \mathrm{~g} \text { to } 10 \mathrm{~g}\end{array}$ & Placebo in MP & $\begin{array}{l}\text { Mean serum } \mathrm{K}^{+} \text {level during } \\
\text { days } 8-29 \text { of the MP }\end{array}$ \\
\hline
\end{tabular}


Table 2. Studies included in the meta-analysis.

\begin{tabular}{|c|c|c|c|c|c|}
\hline Study ID & Design of Study & Outcome & Duration & $\begin{array}{l}\text { MRA NPB (End } \\
\text { of Study) }\end{array}$ & $\begin{array}{l}\text { MRA PBO (End } \\
\text { of Study) }\end{array}$ \\
\hline Rossignol et al., 2020 [21] & $\mathrm{RCT}$ & $\begin{array}{c}\text { Patients taking } \\
\text { spironolactone at week } 12\end{array}$ & 3 months & $48 / 63$ & $41 / 69$ \\
\hline $\begin{array}{c}\text { PEARL HF, Pitt B et al., } \\
2011 \text { [29] }\end{array}$ & RCT & $\begin{array}{l}\text { Change in serum } \mathrm{K}^{+} \text {from } \\
\text { baseline to day } 28\end{array}$ & 28 days & $50 / 55$ & $36 / 49$ \\
\hline PRIORITIZE-HF, 2021 [30] & $\mathrm{RCT}$ & $\begin{array}{l}\text { Percentage of patients } \\
\text { receiving different categories } \\
\text { of RAASi }\end{array}$ & 3 months & $50 / 89$ & $41 / 87$ \\
\hline
\end{tabular}

\subsection{Excluded Studies}

We did not exclude any studies.

3.4. Risk of Bias in Included Studies the Review

The risk of bias is reported in Figure 2.

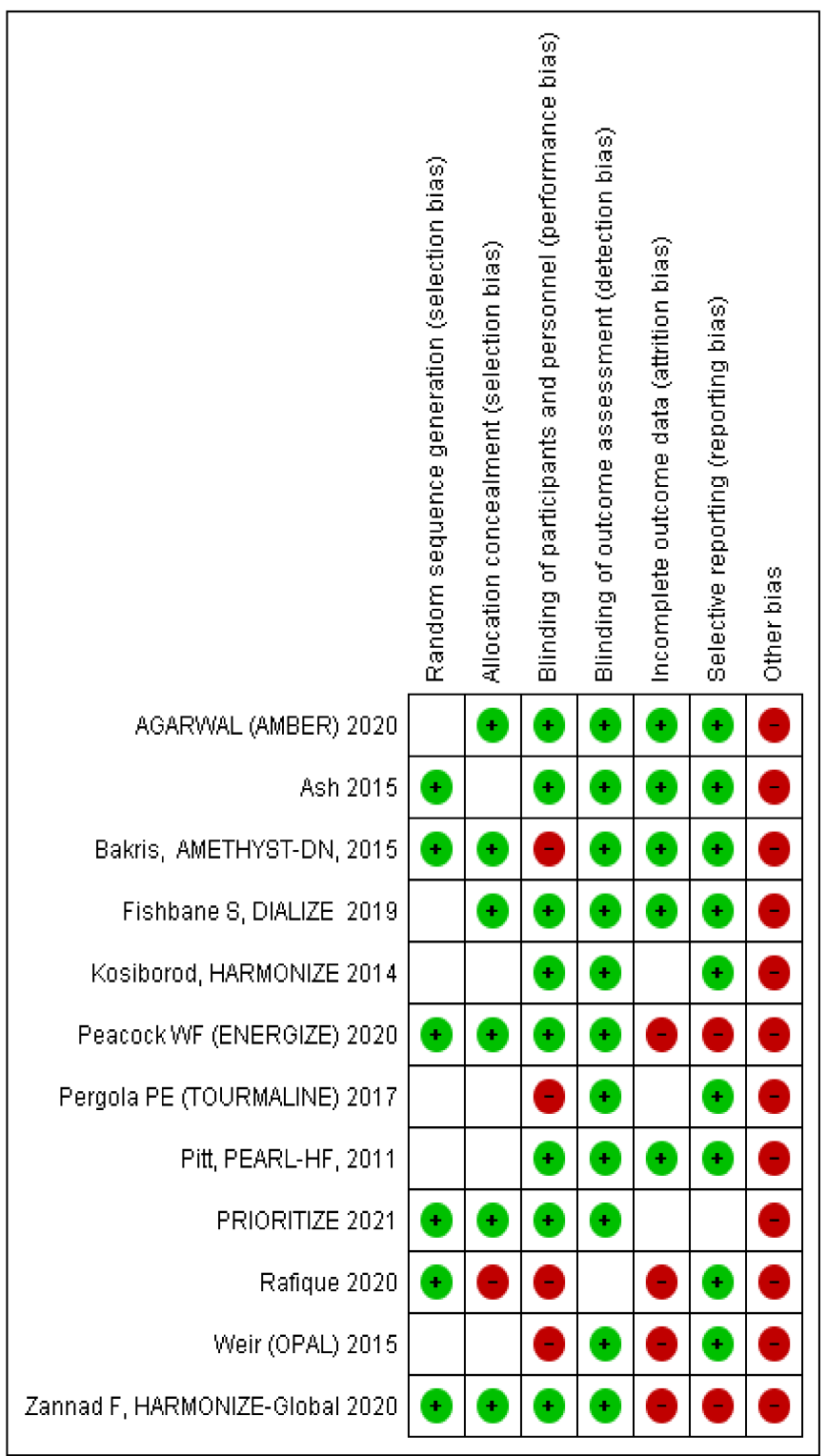

Figure 2. Risk of bias. 


\subsection{Selective Reporting (Reporting Bias)}

We could not make a funnel plot because we had only three studies on the principal outcome.

\subsection{Other Potential Sources of Bias}

All the studies were funded by sponsors, and this may be a source of bias.

\subsection{Effects of Interventions}

NPBs seemed to have an effect on the optimization of MRA therapy, with a risk ratio $(95 \% \mathrm{CI})$ of $1.24(1.09,1.42)$; there was no heterogeneity $\left(\mathrm{I}^{2}=0 \%\right.$, moderate certainty evidence). Patiromer seemed to have an effect on MRA optimization; in two studies with 232 patients, the risk ratio $(95 \% \mathrm{CI})$ was $1.25(1.08,1.45)$ with $\mathrm{I}^{2}=0$ (high certainty evidence). ZSC seemed to have no effect on MRA optimization, as shown by one study with 176 patients (risk ratio $(95 \%$ CI)), $1.19(0.89,1.59)$ (low certainty evidence)) (Figure 3). The subgroup analysis did not show heterogeneity between the subgroups $\left(I^{2}=0 \%\right)$.

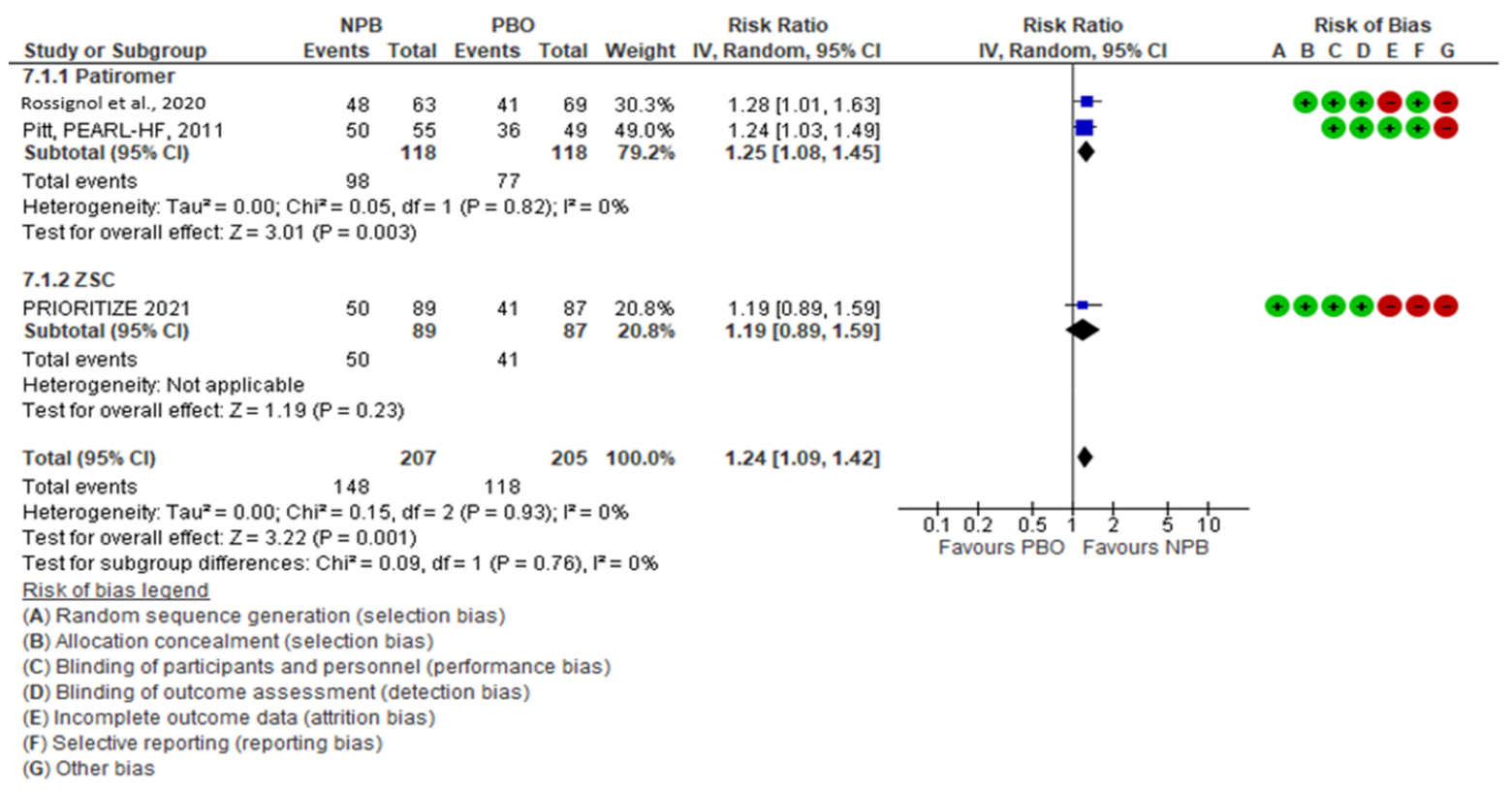

Figure 3. MRA optimization.

We conducted a sensitivity analysis of the MRA optimization outcome. The fixed effects model did not change the magnitude or direction of effect: the NPB RR $(95 \% \mathrm{CI})$ was $1.25(1.09,1.42)$ (Figure 4); the same was observed for the exclusion of the study with a high risk of bias, with an RR $(95 \% \mathrm{CI})$ of $1.25(1.08,1.45)$.

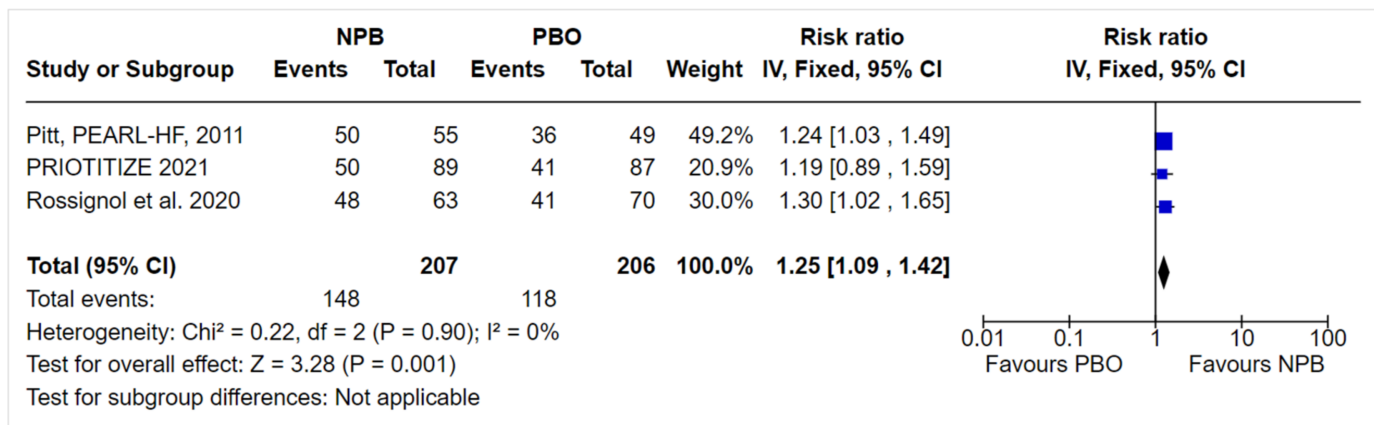

Figure 4. Sensitivity analysis. 
Optimization of ACEi/ARB therapy: There was only one study with Patiromer; it did not seem to have an effect on ACEi/ARB optimization; in 49 patients, the risk ratio (95\% CI) was $1.20(0.85,1.67)$ (low certainty evidence).

Optimization of ARNi therapy: No data were available.

\subsection{Safety}

Patiromer: The most common adverse events were gastrointestinal disorders (12/56 PEARL HF, 9/105 AMETHYST-DN, 5/27 OPAL and 7/63, Rossignol et al., 2020), and hypomagnesemia (13/56 PEARL HF, 19/105 AMETHYST-DN, 3/102 OPAL, and 2/63 Rossignol et al., 2020) [21].

ZSC: The most common adverse events were mild hypokalemia $(\mathrm{S}-\mathrm{K}<3.5 \mathrm{mmol} / \mathrm{L}$, 4/61 HARMONIZE, 7/91 PRIORITIZE), edema (8/61 HARMONIZE, 1/90 PRIORITIZE), and chronic cardiac failure (MEDRA definition) (9/91 PRIORITIZE).

\section{Discussion}

We identified 12 studies randomizing 2800 adult participants evaluating potassium binders for chronic HK (defined as $>5 \mathrm{mmol} / \mathrm{L}$ ). Data for efficacy outcomes included in this review were available in four of these twelve studies: three for MRA therapy (PRIORITIZE HF [30], PEARL HF [29], and Rossignol et al., 2020 [21]) and only one for ACEi/ARB therapy (OPAL HK [32]). In the safety analysis, we included six studies (PRIORITIZE HF [30], HARMONIZE [34], PEARL HF [29], Rossignol et al., 2020 [21], OPAL HK [32], and AMETHYST-DN [24]). New potassium binders seem to have an effect on MRA optimization (moderate certainty evidence). Patiromer seems to have an effect on MRA optimization, while ZSC seems to have no statistically significant effect. It should be noted that the PRIORITIZE study was prematurely terminated because of the COVID-19 pandemic, resulting in a reduced sample size and a high premature treatment discontinuation rate. A sensitivity analysis showed that the evidence was robust; the fixed effects model and random effects model did not change the result. The same happened with the exclusion of the PRIORITIZE study because of the high risk of bias.

The effect of Patiromer on ACEi/ARB optimization was not statistically significant, but the direction of the effect was in accordance with the results of the MRA outcome. MRA therapy is the most discontinued therapy for HK, and the efficacy of its optimization is the answer to unmet medical needs.

The AEs in HF patients with HK treated with Patiromer were similar to those in hyperkalemic patients: GI disorders and hypomagnesemia. The latter had a different incidence between studies in which different doses were used. For ZSC, the most common AEs in hyperkalemic patients included in the RCT were hypokalemia and edema. In our review, hypokalemia was present with an incidence similar to that in other studies in patients without heart failure, while edema was lower. However, chronic cardiac failure (MEDRA definition) was present. The presence of sodium counter-ions in ZSC (400 mg in $5 \mathrm{~g}$ of product) and not in Patiromer may have caused this difference in HF patients. More studies are needed to better understand the long-term safety of ZSCs [35].

\subsection{Overall Completeness and Applicability of Evidence}

There are only four studies with outcomes on RAASi optimization, and all had a limited time of follow-up (1-3 months) with a small number of patients included (99-191). Evidence of the efficacy of NPBs for the initiation and up-titration of MRA therapy has extended the ability of these new substances to maintain RAASi therapy in patients with heart failure. The evidence for the effect of Patiromer on outcomes had high certainty and is in accordance with the effect in patients with HK without HF. The evidence for ZSC had low certainty, and future studies, such as the LIFT study [36], may change the results. 


\subsection{Quality of the Evidence}

We used the GRADE method to assess the quality of the results [37]. The evidence of the effect of NPB on MRA optimization had moderate certainty for imprecision. The effect of Patiromer on MRA optimization had high certainty. The effect of ZSC on outcomes had low certainty for imprecision and risk of bias. The effect of Patiromer on ACEi/ARB therapy had very low certainty for imprecision and risk of bias.

\subsection{Potential Biases in the Review Process}

The authors adopted the following definition of an RR: "A rapid review is a form of knowledge synthesis that accelerates the process of conducting a traditional systematic review through streamlining or omitting various methods to produce evidence for stakeholders in a resource-efficient manner." The authors followed the recommendations reported in Garrity (2021). All the studies included in the RR were supported by sponsors and were impossible to exclude from the RR. The limited number of studies was a constraint on our ability to assess potential reporting bias and selective outcome reporting. The effects of potassium binder interventions on longer-term outcomes were uncertain, and the treatment endpoint was the use of RAASi therapy; if this strategy improves the clinical outcome, a well-designed RCT is needed.

\subsection{Agreements and Disagreements with Other Studies or Reviews}

The reviews published to date have studied the effect of NPBs on serum potassium levels. The focus of our review was to enable RAASi therapy in patients with HF and HK, and it is the first review in this area.

\section{Conclusions}

\subsection{Implications for Practice}

The results of our review indicated that NPBs seem to have an effect on MRA optimization with moderate certainty of evidence. Patiromer seems to have an effect on MRA optimization (high certainty of the evidence), while ZSC seems to have no effect on optimizing MRA therapy (low certainty of evidence).

The effect, quality of evidence, and less damaging AEs in long-term use seem to suggest the use of Patiromer for the optimization of MRA therapy in patients with or at risk of heart failure and HK. This different use of NPB is the same as that reported in other systematic reviews of patients with chronic or recurrent HK $[14,15]$. In the future, this suggestion could change if the publication of new data on the efficacy and safety of ZSC changes its risk/benefit profile.

\subsection{Implications for Research}

There is a gap in knowledge about optimizing ARNi therapy in patients with heart failure and HK and in a head-to-head study between NPBs. Future adequately powered RCTs are needed to assess the benefits and potential harms of potassium binders, and if their use will lead to the optimized use of RAAS inhibitors to improve clinical outcomes in patients with heart failure and HK.

Author Contributions: Conceptualization, Investigation, Methodology, Validation, Writing—original draft, Writing-review \& editing: A.M., S.F., G.G. and D.M. All authors have read and agreed to the published version of the manuscript.

Funding: This work was funded by Fondazione FADOI.

Institutional Review Board Statement: Not applicable.

Informed Consent Statement: Not applicable.

Data Availability Statement: Not applicable.

Conflicts of Interest: The authors declare no conflict of interest. 


\section{References}

1. Ponikowski, P.; Voors, A.A.; Anker, S.D.; Bueno, H.; Cleland, J.; Coats, A.; Falk, V.; González-Juanatey, J.R.; Harjola, V.P.; Jankowska, E.A.; et al. 2016 ESC Guidelines for the diagnosis and treatment of acute and chronic heart failure: The Task Force for the diagnosis and treatment of acute and chronic heart failure of the European Society of Cardiology (ESC) Developed with the special contribution of the Heart Failure Association (HFA) of the ESC. Eur. Heart J. 2016, 37, 2129-2200.

2. Yancy, C.W.; Jessup, M.; Bozkurt, B.; Butler, J.; Casey, D.E., Jr.; Colvin, M.M.; Drazner, M.H.; Filippatos, G.S.; Fonarow, G.C.; Givertz, M.M.; et al. 2017 ACC/AHA/HFSA Focused Update of the 2013 ACCF/AHA Guideline for the Management of Heart Failure: A Report of the American College of Cardiology / American Heart Association Task Force on Clinical Practice Guidelines and the Heart Failure Society of America. Circulation 2017, 136, e137-e161.

3. Epstein, M.; Reaven, N.L.; Funk, S.E.; McGaughey, K.J.; Oestreicher, N.; Knispel, J. Evaluation of the treatment gap between clinical guidelines and the utilization of renin-angiotensin-aldosterone system inhibitors. Am. J. Manag. Care 2015, 21, S212-S220. [PubMed]

4. Rosano, G.; Tamargo, J.; Kjeldsen, K.P.; Lainscak, M.; Agewall, S.; Anker, S.D.; Ceconi, C.; Coats, A.; Drexel, H.; Filippatos, G.; et al. Expert consensus document on the management of hyperkalaemia in patients with cardiovascular disease treated with renin angiotensin aldosterone system inhibitors: Coordinated by the Working Group on Cardiovascular Pharmacotherapy of the European Society. Eur. Heart J. Cardiovasc. Pharmacother. 2018, 4, 180-188. [CrossRef]

5. Collins, A.J.; Pitt, B.; Reaven, N.; Funk, S.; McGaughey, K.; Wilson, D.; Bushinsky, D.A. Association of serum potassium with all-cause mortality in patients with and without heart failure, chronic kidney disease, and/or diabetes. Am. J. Nephrol. 2017, 46, 213-221. [CrossRef]

6. Pitt, B.; Zannad, F.; Remme, W.J.; Cody, R.; Castaigne, A.; Perez, A.; Palensky, J.; Wittes, J. The effect of spironolactone on morbidity and mortality in patients with severe heart failure. Randomized Aldactone Evaluation Study Investigators. N. Engl. J. Med. 1999, 341, 709-717. [CrossRef] [PubMed]

7. Zannad, F.; McMurray, J.J.; Krum, H.; van Veldhuisen, D.J.; Swedberg, K.; Shi, H.; Vincent, J.; Pocock, S.J.; Pitt, B.; EMPHASIS-HF Study Group EMPHASIS-HF Study Group. Eplerenone in patients with systolic heart failure and mild symptoms. N. Engl. J. Med. 2011, 364, 11-21. [CrossRef]

8. Pitt, B.; Remme, W.; Zannad, F.; Neaton, J.; Martinez, F.; Roniker, B.; Bittman, R.; Hurley, S.; Kleiman, J.; Gatlin, M.; et al. Eplerenone, a Selective Aldosterone Blocker, in Patients with Left Ventricular Dysfunction after Myocardial Infarction. N. Engl. J. Med. 2003, 348, 1309-1321. [CrossRef] [PubMed]

9. Savarese, G.; Carrero, J.J.; Pitt, B.; Anker, S.D.; Rosano, G.; Dahlström, U.; Lund, L.H. Factors associated with underuse of mineralocorticoid receptor antagonists in heart failure with reduced ejection fraction: An analysis of 11215 patients from the Swedish Heart Failure Registry. Eur. J. Heart Fail. 2018, 20, 1326-1334. [CrossRef]

10. Rossignol, P.; Lainscak, M.; Crespo-Leiro, M.G.; Laroche, C.; Piepoli, M.F.; Filippatos, G.; Rosano, G.; Savarese, G.; Anker, S.D.; Seferovic, P.M.; et al. Unravelling the interplay between hyperkalaemia, renin-angiotensin-aldosterone inhibitor use and clinical outcomes. Data from 9222 chronic heart failure patients of the ESC-HFA-EORP Heart Failure Long-Term Registry. Eur. J. Heart Fail. 2020, 22, 1378-1389. [CrossRef]

11. Aldahl, M.; Jensen, A.C.; Davidsen, L.; Eriksen, M.A.; Møller Hansen, S.; Nielsen, B.J.; Krogager, M.L.; Køber, L.; Torp-Pedersen, C.; Søgaard, P. Associations of serum potassium levels with mortality in chronic heart failure patients. Eur. Heart J. 2017, 38, 2890-2896. [CrossRef]

12. Li, L.; Harrison, S.D.; Cope, M.J.; Park, C.; Lee, L.; Salaymeh, F.; Madsen, D.; Benton, W.W.; Berman, L.; Buysse, J. Mechanism of Action and Pharmacology of Patiromer, a Nonabsorbed Cross-Linked Polymer That Lowers Serum Potassium Concentration in Patients With Hyperkalemia. J. Cardiovasc. Pharmacol. Ther. 2016, 21, 456-465. [CrossRef]

13. Stavros, F.; Yang, A.; Leon, A.; Nuttall, M.; Rasmussen, H.S. Characterization of structure and function of ZS-9, a K+ selective ion trap. PLoS ONE 2014, 9, e114686. [CrossRef]

14. Meaney, C.J.; Beccari, M.V.; Yang, Y.; Zhao, J. Systematic Review and Meta-Analysis of Patiromer and Sodium Zirconium Cyclosilicate: A New Armamentarium for the Treatment of Hyperkalemia. Pharmacotherapy 2017, 37, 401-411. [CrossRef] [PubMed]

15. Shrestha, D.B.; Budhathoki, P.; Sedhai, Y.R.; Baniya, R.; Cable, C.A.; Kashiouris, M.G.; Dixon, D.L.; Kidd, J.M.; Adhikari, Y.; Marasini, A.; et al. Patiromer and Sodium Zirconium Cyclosilicate in Treatment of Hyperkalemia: A Systematic Review and Meta-Analysis. Curr. Ther. Res. Clin. Exp. 2021, 95, 100635. [CrossRef]

16. Natale, P.; Palmer, S.C.; Ruospo, M.; Saglimbene, V.M.; Strippoli, G.F. Potassium binders for chronic hype Potassium binders for chronic hyperkalaemia in people with chronic kidney disease. Cochrane Database Syst. Rev. 2020, 6, CD013165.

17. Zhang, Y.; Xu, R.; Wang, F.; Liu, Y.; Xu, J.; Zhao, N.; Cheng, F.; Long, L.; Jia, J.; Lin, S. Effects and Safety of a Novel Oral Potassium-Lowering Drug-Sodium Zirconium Cyclosilicate for the Treatment of Hyperkalemia: A Systematic Review and Meta-Analysis. Cardiovasc. Drugs Ther. 2021, 35, 1057-1066. [CrossRef]

18. Higgins, J.; Thomas, J.; Chandler, J.; Cumpston, M.; Li, T.; Page, M.; Welch, V. Cochrane Handbook for Systematic Reviews of Interventions; Version 6.2 (Updated February 2021). Available online: https://training.cochrane.org/handbook/current (accessed on 8 September 2021).

19. Higgins, J.P.; Thompson, S.G.; Deeks, J.J.; Altman, D.G. Measuring inconsistency in meta-analyses. BMJ 2003, 327, 557-560. [CrossRef] [PubMed] 
20. Pitt, B.; Bakris, G.L.; Bushinsky, D.A.; Garza, D.; Mayo, M.R.; Stasiv, Y.; Christ-Schmidt, H.; Berman, L.; Weir, M.R. Effect of patiromer on reducing serum potassium and preventing recurrent hyperkalaemia in patients with heart failure and chronic kidney disease on RAAS inhibitors. Eur. J. Heart Fail. 2015, 17, 1057-1065. [CrossRef] [PubMed]

21. Rossignol, P.; Williams, B.; Mayo, M.R.; Warren, S.; Arthur, S.; Ackourey, G.; White, W.B.; Agarwal, R. Patiromer versus placebo to enable spironolactone use in patients with resistant hypertension and chronic kidney disease (AMBER): Results in the pre-specified subgroup with heart failure. Eur. J. Heart Fail. 2020, 22, 1462-1471. [CrossRef]

22. Agarwal, R.; Rossignol, P.; Romero, A.; Garza, D.; Mayo, M.R.; Warren, S.; Ma, J.; White, W.B.; Williams, B. Patiromer versus placebo to enable spironolactone use in patients with resistant hypertension and chronic kidney disease (AMBER): A phase 2, randomised, double-blind, placebo-controlled trial. Lancet 2019, 394, 1540-1550. [CrossRef]

23. Ash, S.R.; Singh, B.; Lavin, P.T.; Stavros, F.; Rasmussen, H.S. A phase 2 study on the treatment of hyperkalemia in patients with chronic kidney disease suggests that the selective potassium trap, ZS-9, is safe and efficient. Kidney Int. 2015, 88, 404-411. [CrossRef]

24. Bakris, G.L.; Pitt, B.; Weir, M.R.; Freeman, M.W.; Mayo, M.R.; Garza, D.; Stasiv, Y.; Zawadzki, R.; Berman, L.; Bushinsky, D.A.; et al. Effect of Patiromer on Serum Potassium Level in Patients With Hyperkalemia and Diabetic Kidney Disease: The AMETHYST-DN Randomized Clinical Trial. JAMA 2015, 314, 151-161. [CrossRef]

25. Fishbane, S.; Ford, M.; Fukagawa, M.; McCafferty, K.; Rastogi, A.; Spinowitz, B.; Staroselskiy, K.; Vishnevskiy, K.; Lisovskaja, V.; Al-Shurbaji, A.; et al. A phase 3b, randomized, double-Blind, placebo-controlled study of sodium zirconium cyclosilicate for reducing the incidence of predialysis hyperkalemia. J. Am. Soc. Nephrol. 2019, 30, 1723-1733. [CrossRef]

26. Anker, S.D.; Kosiborod, M.; Zannad, F.; Piña, I.L.; McCullough, P.A.; Filippatos, G.; van der Meer, P.; Ponikowski, P.; Rasmussen, H.S.; Lavin, P.T.; et al. Maintenance of serum potassium with sodium zirconium cyclosilicate (ZS-9) in heart failure patients: Results from a phase 3 randomized, double-blind, placebo-controlled trial. Eur. J. Heart Fail. 2015, 17, 1050-1056. [CrossRef]

27. Peacock, W.F.; Rafique, Z.; Vishnevskiy, K.; Michelson, E.; Vishneva, E.; Zvereva, T.; Nahra, R.; Li, D.; Miller, J. Emergency Potassium Normalization Treatment Including Sodium Zirconium Cyclosilicate: A Phase II, Randomized, Double-blind, Placebocontrolled Study (ENERGIZE). Acad. Emerg. Med. 2020, 27, 475-486. [CrossRef]

28. Pergola, P.E.; Spiegel, D.M.; Warren, S.; Yuan, J.; Weir, M.R. Patiromer Lowers Serum Potassium When Taken without Food: Comparison to Dosing with Food from an Open-Label, Randomized, Parallel Group Hyperkalemia Study. Am. J. Nephrol. 2017, 46, 323-332. [CrossRef]

29. Pitt, B.; Anker, S.D.; Bushinsky, D.A.; Kitzman, D.W.; Zannad, F.; Huang, I.Z.; PEARL-HF Investigators. Evaluation of the efficacy and safety of RLY5016, a polymeric potassium binder, in a double-blind, placebo-controlled study in patients with chronic heart failure (the PEARL-HF) trial. Eur. Heart J. 2011, 32, 820-828. [CrossRef] [PubMed]

30. ClinicalTrials.gov [Internet]. Bethesda (MD): National Library of Medicine (US). Identifier NCT03532009, Potassium Reduction Initiative to Optimize RAAS Inhibition Therapy with Sodium Zirconium Cyclosilicate in Heart Failure (PRIORITIZE HF), 22 May 2018. Available online: https:/ / clinicaltrials.gov / ct2/show / study / NCT03532009?term=prioritize+hf\&draw=2\&rank=1 (accessed on 27 October 2021).

31. Rafique, Z.; Liu, M.; Staggers, K.A.; Minard, C.G.; Peacock, W.F. Patiromer for Treatment of Hyperkalemia in the Emergency Department: A Pilot Study. Acad. Emerg. Med. 2020, 27, 54-60. [CrossRef] [PubMed]

32. Weir, M.R.; Bakris, G.L.; Bushinsky, D.A.; Mayo, M.R.; Garza, D.; Stasiv, Y.; Wittes, J.; Christ-Schmidt, H.; Berman, L.; Pitt, B.; et al. Patiromer in patients with kidney disease and hyperkalemia receiving RAAS inhibitors. N. Engl. J. Med. 2015, 372, $211-221$. [CrossRef] [PubMed]

33. Zannad, F.; Hsu, B.G.; Maeda, Y.; Shin, S.K.; Vishneva, E.M.; Rensfeldt, M.; Eklund, S.; Zhao, J. Efficacy and safety of sodium zirconium cyclosilicate for hyperkalaemia: The randomized, placebo-controlled HARMONIZE-Global study. ESC Heart Fail. 2020, 7, 54-64. [CrossRef] [PubMed]

34. Kosiborod, M.; Rasmussen, H.S.; Lavin, P.; Qunibi, W.Y.; Spinowitz, B.; Packham, D.; Roger, S.D.; Yang, A.; Lerma, E.; Singh, B. Effect of sodium zirconium cyclosilicate on potassium lowering for 28 days among outpatients with hyperkalemia: The HARMONIZE randomized clinical trial. JAMA 2014, 312, 2223-2233. [CrossRef] [PubMed]

35. Epstein, M. Renin-Angiotensin-Aldosterone System Inhibition and Mineralocorticoid Receptor Antagonists: The Overriding Importance of Enablers and Dampers. Kidney Int. Rep. 2021, 6, 869-871. [CrossRef] [PubMed]

36. Murphy, D.; Ster, I.C.; Kaski, J.C.; Anderson, L.; Banerjee, D. The LIFT trial: Study protocol for a double-blind, randomised, placebo-controlled trial of K+-binder Lokelma for maximisation of RAAS inhibition in CKD patients with heart failure. $B M C$ Nephrol. 2021, 22, 254. [CrossRef]

37. Guyatt, G.; Oxman, A.D.; Akl, E.A.; Kunz, R.; Vist, G.; Brozek, J.; Norris, S.; Falck-Ytter, Y.; Glasziou, P.; DeBeer, H.; et al. GRADE guidelines: 1. Introduction-GRADE evidence profiles and summary of findings tables. J. Clin. Epidemiol. 2011, 64, 383-394. [CrossRef] [PubMed] 